\section{PROPUESTAS METODOLÓGICAS PARA LA INVESTIGACIÓN JURÍDICA APLICADA*}

\author{
Gisela María Pérez Fuentes $^{* *}$ \\ Universidad Juárez de Tabasco en México
}

Fecha de recepción: 11 septiembre de 2009

Fecha de aceptación: 15 de octubre de 2009

"Existe el peligro constante de que el material de la instrucción sistemática sea meramente el tema de estudio de las escuelas, aislado de los temas de las experiencias de la vida."

John Dewey

\section{Resumen}

En las escuelas de Derecho hace años que algo no está dando el resultado esperado, los alumnos por una parte consideran que el estudio de la carrera es fácil, por otra parte, los resultados cada vez más altos de titulación no implican que estos recién graduados tengan una preparación real para afrontar el ejercicio de la profesión, la creación de escuelas privadas hasta incluso nivel Doctorado, han permitido que existan titulaciones en alto nivel de posgrado sin que se acompañe a un proceso de investigación previa. La situación es más generalizada en nivel licenciatura. El artículo se encamina en primer lugar a buscar causas

El artículo es producto de la investigación registrada en la División Académica de Ciencias Sociales y Humanidades, que tiene como objetivo el perfeccionamiento y actualización de la enseñanza del derecho civil, y aparece con varios productos parciales entre los que se encuentra el Manual de la Teoría General de las Obligaciones, según el Código Civil de Tabasco, que no coincide en este Libro del Código, con el Código Civil del Distrito Federal.

** Abogada no ejerciente, pertenece al Ilustre Colegio de Abogados de Madrid, es actualmente, profesora Investigadora de la Universidad Juárez de Tabasco en México. Pertenece al Sistema Nacional de Investigadores de México Nivel I. de esta realidad y posteriormente establece propuestas basadas en experiencias propias y en el derecho comparado.

\section{Palabras clave}

Investigación jurídica, positivismo, aprendizaje por competencia, métodos integrativos

\section{METHODOLOGICAL PROPOSALS FOR APPLIED LEGAL RESEARCH}

\begin{abstract}
In law schools for years that something is not giving the expected result, students on the one hand consider the study of the race is easy, on the other hand, the results increasingly higher degree does not mean that these new graduates have real preparation to address the practice of the profession, the establishment of private schools to even $\mathrm{PhD}$ level, have allowed that there are higher degrees in graduate level without accompanying a previous investigation process. The situation is more widespread in undergraduate level. The article is headed in the first place to look for causes of this situation and then sets out proposals based on personal experiences and comparative law.
\end{abstract}

\section{Keywords}

Legal research, positivism, competitive learning, integrative methods.

\section{INTRODUCCIÓN}

La era de la sociedad de la información, la globalización y el constante intercambio de personas y mercados de distintos países ha llenado el mundo y las exigencias que la sociedad le hace al derecho son muy distintas a la de principios del siglo $\mathrm{XX}$, pero en el viejo $\mathrm{y}$ anquilosado camino de la investigación jurídica en el derecho hispano-americano, prima aún, la 
reflexión doctrinal o dogmática por una parte, o los extremos del pragmatismo jurídico muy cercanos a un mecanicismo tal, que parece inducir a los estudiosos del derecho a sistemas cerrados incapaces de dar respuestas efectivas, por ejemplo, la autonomía de la voluntad en la bilateralidad contractual, ha cedido el paso a los contratos de adhesión, a nuestras vidas llegó la globalización, América Latina y la propia Europa no se escapa de la redimensión universitaria, para ello, las ecuaciones silogísticas propias del Poder Judicial tradicional se sustituyen por las nuevas teorías de la argumentación, los notarios, se encuentran cada vez más con nuevos tipos de actos jurídicos muy alejados de los conocidos por el derecho de propiedad o la teoría de los contratos, en los que compraventa, donación, cesión de derechos, por citar algunos ejemplos, eran los únicos panes nuestros de cada día.

En estas profesiones, puede aparecer por ejemplo, el derecho de superficie, de naturaleza anti-romana, como una forma de solución ante la inversión extranjera. En la actualidad, la misma competitividad necesita dar soluciones jurídicas a nuevas situaciones económicas, jurídicas y sociales, y la Universidad es un camino ideal para dar respuestas de investigación a tales fenómenos socio-económicos y jurídicos, sin embargo, el laboratorio universitario debe ceder conjuntamente con su discurso dogmático abstracto, retórico y sólo entendible para el "sabio jurista". Es la hora de aprender haciendo y ya es hora de romper el paradigma de la teoría alejada de la realidad, por eso es necesario asumir la actualización metodológica en la investigación jurídica con la incorporación de los métodos interdisciplinarios aquí desarrollados como única vía para lograr soluciones jurídicas acordes con la globalización y contemporaneidad, ésta es nuestra hipótesis a demostrar en el siguiente trabajo que a continuación presentamos.

\section{DE LA DOGMÁTICA Y EL POSITIVISMO A LA INVESTIGACIÓN APLICADA}

El derecho se consideró ciencia y no especulación a partir de la postura kelseniana ${ }^{1}$, cierto es que el positivismo jurídico surgió como la respuesta a distintas concepciones iusnaturalistas en diferentes épocas históricas donde se vinculaba al derecho con los valores éticos impuestos por voluntad divina o por el convenio social, fijado por la razón humana.

¿Es el derecho una ciencia? Ante esta pregunta, es necesario reconocer que en la corriente positivista, el derecho, por una parte fue tratado como una ciencia natural pues se consideró que tenía un objeto empírico determinado que eran las leyes; por otra parte, el derecho fue visto como una ciencia formal, identificado por definiciones de corte memorístico. Ante estas dos vertientes el derecho ha sido definido durante gran tiempo como el conjunto de normas propias de un ordenamiento jurídico.

La posición "científica del derecho" ha marcado en la enseñanza jurídica, un distanciamiento de la práctica que implica una carrera terminada sin eficacia en la toma de decisiones jurídicas, esta realidad ha afectado también y mucho a la investigación. Es imprescindible aclarar que la definición señalada limita el concepto del derecho a ley y cierra así su evolución como ciencia. Precisamente uno de los cuestionamientos realizados en la "revolución investigativa del

\footnotetext{
Decía RECASENS: “..Kelsen ha producido el mejor estudio del derecho desde el punto de vista de la normatividad jurídica. Su teoría pura del derecho ha logrado calar con la máxima hondura en todas las estructuras lógicas y reales del derecho...Pero Kelsen ha olvidado que la normatividad del derecho es tan sólo la dimensión formal de lo jurídico, y ha olvidado que esa normatividad jurídica no se halla en situación de pureza", RECASENS, Luis, "Balance de la Teoría Pura del derecho" en Boletín Mexicano de Derecho Comparado, México, nueva serie, año VII número especial, número 19, Enero-Abril de 1974, p. 167.
} 
derecho" es el reconocimiento de la ambigüedad de la pregunta ¿qué es derecho? como dice Carrió: "la palabra derecho tiene muchos significados, no uno solo, a la ambigüedad de la interrogante ¿Qué es derecho? es incierto si lo que nos piden es que se indique el significado o significados de la palabra "derecho" o que se describan las propiedades o características típicas de los fenómenos usualmente designados con ella o alguna otra cosa ${ }^{2}$.

A pesar de la gran aportación de Kelsen al derecho como ciencia, críticos y defensores actuales coinciden en que este eminente jurista en su teoría pura del derecho, negó la posibilidad de crear nuevo derecho por vía de la interpretación partiendo de la falta de aceptación de lagunas en el orden jurídico ${ }^{3}$.

Kelsen se opuso a la jurisprudencia de conceptos y con esto negó la posibilidad de crear nuevo derecho por vía de interpretación, no reconociendo así las lagunas en el orden jurídico, y en este sentido sí coinciden todos los autores que si en un orden jurídico no resulta factible reconocer lagunas, tampoco es posible admitir que la ciencia jurídica se reconozca como ciencia y mucho menos, la posibilidad de que exista una nueva norma que subsane dicha laguna ${ }^{4}$.

El positivismo ha influido sin duda en la enseñanza del derecho de la mayoría de las Universidades latinoamericanas, propiciando una enseñanza "cerrada", "exacta", dificultando así la adaptación de las instituciones jurídicas al desarrollo del hecho científico, social y político. El derecho mexicano del siglo XX, por ejemplo, estuvo permeado por ésta corriente filosófica denominada positivismo jurídico, caracterizada ésta porque el jurista como científico del

2 CARRIÓ, G.R; Notas sobre derecho y lenguaje, Buenos Aires, 1990, p. 68.

3 COSSÍO DÍAZ, José Ramón; Derecho y análisis económico, Editorial Fondo de Cultura Económica -ITAM, México, $2^{\mathrm{a}}$ reimpresión, 2008, p. 81.

$4 \quad$ Ibídem, p. 82. derecho quedó limitado a recibir el ordenamiento que estudiaba como única fuente de conocimiento, sin capacidad de contextualizar histórica y socialmente la eficacia de la norma ${ }^{5}$. Para esta posición filosófica que influyó en la ciencia toda y también en el derecho, las concepciones morales no influían en la solución de conflictos jurídicos. Al positivismo jurídico como método de análisis jurídico, no le interesó tratar de explicar el contenido normativo y su relación con el acontecer histórico social, sino sólo se limitó a la descripción de la forma legal, es decir, la definición de conceptos abstractos y a-históricos. La corriente positivista por supuesto, ha sido el método de la enseñanza del derecho en los países de América ${ }^{6}$.

\subsection{El cambio de paradigma en las Ciencias Sociales, en el Derecho y en su aprendizaje}

A pesar de las indiscutibles aportaciones del positivismo a la evolución del Derecho, hemos sostenido que dicha corriente permeó de una neutralidad valorativa en el cumplimiento de las leyes, entendiendo a éstas en el sentido clásico de que las mismas describen, explican y predicen los fenómenos. Es Popper el que ataca el método silogístico, es decir, que una hipótesis no se deduce de la premisa mayor y menor, sino del método de la construcción

Cfr. FIX-FIERRO, Héctor y LÓPEZ-AYLLÓN, Sergio. "La educación jurídica en México. Un panorama general" en: GONZÁLEZ MARTíN, Nuria (Coord.), Estudios jurídicos en homenaje a Marta Morineau, Tomo II: Sistemas jurídicos contemporáneos. Derecho comparado. Temas diversos, México, UNAM, Instituto de Investigaciones jurídicas, pp. 277-323.

6 Señala ESCOBAR MARTÍNEZ, Lina Marcela: "El derecho se ha ocupado de reconstruir las consagraciones constitucionales del derecho a la educación, así como su reglamentación y legalización en los diferentes períodos históricos, con lo cual el análisis ha estado focalizado en la normatividad, quedándose en un enfoque netamente positivista..." cita en "El Derecho a la Educación en Colombia 1830-1853. La historia en el presente" en Revista Prolegómenos- Derecho y Valores, Colombia, Universidad Militar Nueva Granada, Volumen XII, No. 23, Enero-Junio de 2009, p. 59. 
racional o lógica. Esto es muy importante para el derecho porque permite desplazar en el proceso de investigación la fase de explicación del sujeto separado de su objeto, y que ha llevado en múltiples ocasiones a resultados académicos descriptivos sin un resultado verdaderamente valorativo ${ }^{7}$.

El carácter avalorativo del derecho impuso en la enseñanza un método de aprendizaje de carácter memorístico. La realidad anterior permitió que los estudios de la carrera de Derecho fueran estrictamente apegados a la norma, sin incorporar el cuestionamiento del conocimiento en la elaboración de conceptos y ello impuso que el método memorístico primara en las formas cognoscitivas fundamentales de aprendizaje jurídico, donde los manuales o resúmenes de clases de un profesor eminente eran indicados como bibliografía en uno y muchos años subsiguientes, aún cuando las circunstancias sociales podían ya no ajustarse al contenido, en México por ejemplo, existieron otros factores locales muy importantes, en un país con treinta y un estados y un Distrito Federal, la fuente bibliográfica fundamental, procedente de los reconocidos profesores de la UNAM, trataba una normativa no acorde con la de los Estados que tienen su propia Constitución y Códigos estatales; la situación se agravaba cuando, suponemos, por una excesiva perspectiva positivista, la doctrina y la jurisprudencia resultaban muy omisas en sus manuales.

La enseñanza del derecho a través de la lógica tradicional de García Máynez ${ }^{8}$ donde se apli-

POPPER, Karl, La lógica de la investigación cientifica. Trad. Víctor Sánchez de Zavala, $1^{\mathrm{a}}$ Ed., $11^{\mathrm{a}}$ reimp. Madrid, Tecnos, 1973, 260-261.

8 Con indiscutible valor, una de las obras que considero más estudiadas del profesor mexicano Eduardo García Máynez, es Introducción a la lógica jurídica, Edición Fontamara, México, 2007, sin embargo su obra ha sido considerada como semi-analítica pues aparece enmarcada dentro de la lógica del método deductivo propio del positivismo, sin dejar de reconocer su consideraciones humanistas, Guillermo Hurtado hace un análisis evoluti- caba un método de interpretación deductiva del derecho, conllevó también a un mecanicismo interpretativo, que concluyó con absurdos en los que el estudiante manifestaba algo sin reconocer su significado9. En las clases de licenciatura por ejemplo, hemos vivido el ejemplo de solicitarle a un estudiante la estructura del Código Civil de Tabasco ${ }^{10}$, sin embargo y a pesar de estar observando que tienen en sus manos este texto legal, repiten lo que aparece en un libro de texto también indicado en la bibliografía y que como se refiere al derecho propio del Distrito Federal, no coincide con el nuestro, cuando interpelas al estudiante, la primera reacción es de desconcierto, que manifiesta: no es posible si yo lo leí en el libro".

Por estas realidades propias de la universidad del siglo XX, se trabaja en una nueva concepción de enseñanza basada en una investigación aplicada, que en el ámbito del derecho se refiere a la aplicación de técnicas de investigación llamadas humanísticas, sociológicas, realistas, "prácticas o materiales" por oposición a las que utiliza la investigación fundamental: técnicas, teóricas, dogmáticas, conceptuales o formales ${ }^{11}$ Como señala González Galván:

vo de la lógica jurídica formalista desarrollada por García Máynez a las propuestas metodológicas argumentativas que comenzaron en la UNAM desde mediados de los años 1970. Cfr. HURTADO, Guillermo, "Eduardo García Máynez y la filosofía científica en México" 2a Parte, Isonomía: Revista de teoría y filosofía del Derecho, México, No. 16 , abril de 2002, pp. 71-88.

9 No se menosprecia el necesario valor memorístico que necesita un profesional para reconocer características propias de su actuar profesional, la referencia se realiza en la incapacidad de los estudiantes para aplicar conocimientos teóricos a la realidad práctica a través de una investigación aplicada.

10 Tabasco es uno de los Estados del sureste mexicano, donde la autora imparte clases e investiga en la Universidad Pública del lugar (Universidad Juárez Autónoma de Tabasco).

11 GONZÁLEZ GALVÁN, Jorge Alberto, "Enseñanza de la metodología de la investigación aplicada al Derecho: ¿Ciencia Jurídica o Ciencia Ficción? Un ensayo de autocrítica”, Boletín Mexicano de Derecho Comparado, 
“...se ha considerado que el ejercicio profesional del licenciado en derecho no es investigar... por ello es necesario considerar que la enseñanza de las técnicas de investigación no debe ser el monopolio de la formación jurídica en los postgrados, ni el ejercicio profesional de la investigación debe ser el monopolio de los centros o institutos universitarios..." 12

La nueva estrategia en la enseñanza universitaria está también vinculada con el proceso de globalización que en leguaje académico ha quedado identificado a través de las redes como ya avizoraba en 1999, Galo Burbano ${ }^{13}$.

\subsection{De la historia crítica a la sociología jurídica como métodos integrativos de docencia e investigación jurídica}

La función efectiva de la historia en el derecho, tanto en la docencia como en la investigación, no debe estar ya más vinculada con una actividad contemplativa, y es que la historia no sirve para justificar el derecho sino para explicarlo. La historia social puede ofrecer argumentos para demostrar el carácter anacrónico de una norma y para propiciar su modificación, por otra parte, la historia dogmática permite un papel esclarecedor a través de la reconstrucción doctrinaria de un conjunto normativo que

México, Sexagésimo Aniversario, Número conmemorativo 1948-2008, pp. 469-510.

12 GONZÁLEZ GALVÁN, óp. cit. p. 470.

13 Señalaba el autor: "La conformación de redes de instituciones de enseñanza superior y de investigación que han surgido con vigor en los últimos años en América Latina y el Caribe, constituye una metodología innovadora en el fortalecimiento de las capacidades de los países en desarrollo... si las instituciones de educación superior no adoptan la nueva cultura internacional, y no establecen políticas y estrategias que la integren a la dimensión internacional, abandonarán su vocación primaria: la universalidad del conocimiento" Cfr. BURBANO LÓPEZ, Galo, "La educación superior en la segunda mitad del Siglo XX. Los alcances del cambio en América Latina y el Caribe" Revista Iberoamericana de Educación, (OEI), España, No. 21, Universidad Siglo XXI. Septiembre - Diciembre de 1999, p. 20, http:// www.rieoei.org/rie21f.htm. ofrece material útil para identificar cambios de significado y valoración del derecho. Ej. el reconocimiento de la tendencia de objetivización de la culpa en materia de responsabilidad civil, no soluciona por ejemplo, que ocurran menos accidentes, entonces estos esquemas jurídicos deben entrar a un análisis de carácter más real e integrativo.

Una vez más el paradigma positivista-formalista, no soluciona los diversos problemas que encuentra el derecho para que se convierta en efectivo, pero el proceso mismo de la investigación no tiene etapas ni divisiones, es por ello que lo normativo formalista y lo sociológico son caras del mismo fenómeno. Si se considera que sólo es válido el paradigma socio-jurídico (eficacia, empirismo, tecnicismo pragmático) para investigar el derecho, se omiten los argumentos de vigencia y validez, por ejemplo.

En la vinculación entre derecho y sociología jurídica, existe una prelación necesaria del derecho en cuanto a conocimiento previo para posteriormente aplicar la sociología jurídica. En esta última disciplina, por ejemplo el asunto no radica en determinar la conducta que constituye un homicidio sino que con anterioridad es imprescindible establecer primeramente el conjunto de elementos que conforman el homicidio como tipo penal para posteriormente contrastar la conducta con él y establecer entonces si esa conducta encaja en el tipo penal ${ }^{14}$. A través de la sociología jurídica se consideran elementos subjetivos que han definido la conducta que se tipifica en la norma, tales como los celos, el odio, la venganza y que se pueden convertir en las causas de la acción ${ }^{15}$. La sociología jurídica explica entonces las conductas humanas relacionadas con las normas jurídicas a fin de prevenirlas, el jurista no tiene que establecer cómo la conducta humana opera dentro de la

\footnotetext{
14 COSSÍO DÍAZ, José Ramón, op.cit. p. 167.

15 Ibídem, p. 169.
} 
función legislativa y jurisdiccional, sino estudiar las conductas humanas en tanto vinculación de instituciones normativas, así que el estudio de las conductas humanas estarán en función del establecimiento del posible significado de las normas ${ }^{16}$. En plena correspondencia con García Jaramillo ${ }^{17}$, la vida del derecho no ha sido la lógica, ha sido la experiencia, esto es, el derecho debe reflejar la realidad social, y no intentar que la realidad social se adapte en las normas obsoletas.

\section{EL MÉTODO ACTIVO DE ENSEÑANZA: ¿CLASE MAGISTRAL O ESTUDIO DE CASOS?}

Es innegable poner en movimiento el método activo de aprendizaje frente al tradicional y en desuso método memorístico ${ }^{18}$, pero ello debe hacerse con pedagogía, elemento no aplicado en los estudios universitarios de derecho, donde la mayoría de los profesores, tienen un desconocimiento de las técnicas pedagógicas. Pero un simple ejemplo sobre un caso de la vida real, y el análisis de su solución jurídica normativa, o la interpretación de una sentencia, aplicada al propio caso, resulta hoy insuficiente para preparar de forma activa al estudiante de derecho. La pedagogía jurídica implica cambios que operan tanto en los contenidos informativos, como en la metodología de la enseñanza,

\section{Ibidem, p. 109.}

17 GARCÍA JARAMILLO, Leonardo, "El "Nuevo Derecho" en Colombia": ¿Entelequia innecesaria o novedad pertinente?, Revista de Derecho, Colombia, Universidad del Norte, No. 29, Junio de 2008, p. 296.

18 Se reitera que la crítica al modelo memorístico está vinculada a la etapa donde la posición reiterativa de conceptos por parte del estudiante, eliminaba toda vinculación con la realidad social, en esta posición, WITKER, Jorge, "Algunas reflexiones en torno a la reforma curricular de los estudios jurídicos en América Latina", en CIENFUEGOS SALGADO, David y MACÍAS VÁZQUEZ, María Carmen (Coord.), Estudios en homenaje a Marcia Muñoz de Alba Medrano. La enseñanza del derecho, México, UNAM, Instituto de Investigaciones Jurídicas, 2007, pp. 485-500. acorde con sustanciales variaciones en los objetivos que una escuela de derecho de nivel universitario persiga, de forma que los planes y programas sean capaces de aplicar métodos de evaluación. Por otra parte debe insistirse en la interdisciplinariedad como trandisciplinariedad, es decir, incorporar el pensamiento complejo, es decir que podamos trabajar con médicos, con economistas, estudiar el derecho laboral como parte del derecho de empresa, por otra parte, en el área de la formación del abogado, el método será el camino que elegimos para llegar a formar un profesional crítico, creador y útil a la sociedad en que sirve, y en definitiva, como señala Jorge Witker ${ }^{19}$, se hace necesario diseñar una apertura de conocimiento jurídico que permita superar los paradigmas que heredamos de los años treinta, cuarenta, y cincuenta del siglo pasado, y crear nuevos enfoques que adecuen el derecho a las necesidades de la sociedad actual

Pero en la búsqueda de un método alternativo al tradicional, se ha negado en el extremo opuesto, la calidad pedagógica de la clase magistral. A nuestro entender, la debilidad más importante de la conferencia magistral es, que conduce a una estructura y visión conceptual del derecho, inhibiendo entonces la actitud crítica del alumno ante las afirmaciones del profesor $^{20}$.

El punto de partida para un método activo de enseñanza implica un estudio previo del estudiante, que se sustenta y prueba a través de la elaboración de un material donde se plasmen los principios generales de carácter pedagógico

19 WITKER Jorge, "Hacia una investigación jurídica integrativa" Boletín Mexicano de Derecho Comparado. Nueva Serie, año XLI, número 122, mayo-agosto, 2008, p. 944 .

20 En esta misma posición, WITKER, Jorge en Técnicas de la enseñanza del Derecho. Serie J. Enseñanza del Derecho y Material Didáctico, Número 7, 4a edición, 1985, Instituto de investigaciones Jurídicas, UNAM, p. 131. 
a evaluar en el caso que se trate, sólo así, se podrá estimular la participación del estudiante, alejada de la improvisación. El trabajo del alumno estará sustentado en las indicaciones previas del profesor donde existirá un planteamiento del problema y unas preguntas que permitirán otorgar un orden lógico a la investigación de clase.

\subsection{Una reflexión ante el pragmatismo jurídico en América Latina}

En el rompimiento del paradigma de la enseñanza y de la investigación jurídica se trata de romper con la actitud pasiva del estudiante o investigador que reproduce criterios de otros por eso ha existido una tendencia al análisis empírico del derecho a través de la valoración del estudio de casos, ${ }^{21}$ propios del sistema norteamericano, originario de ese país y a los que autores como Serna de la Garza ${ }^{22}$ califican como un método también pasivo de la enseñanza, y que para nosotros es limitado en cuanto a la creatividad propia de la investigación.

Fue Christopher Columbus Langdell, decano de la escuela de derecho de Harvard en 1870, el que introdujo las modificaciones en la enseñanza del derecho en cuanto a dos pilares modificativos: I. La sustitución del libro de texto por el libro de casos, II. La sustitución de la cátedra magistral por el método socrático en el salón de clases de forma que el profesor

$21 \quad$ WITKER critica las tendencias en Universidades mexicanas a privilegiar la función litigiosa del abogado en detrimento de funciones polivalentes, cfr. "Algunas reflexiones en torno a la reforma curricular de los estudios jurídicos en América Latina" en Estudios en homenaje a Marcia Muñoz de Alba Medrano. La enseñanza. 2007, p. 486.

22 SERNA DE LA GARZA, José María, "El método de casos: reflexiones sobre el cambio en la metodología de la enseñanza del derecho en México", en SERNA DE LA GARZA, José María (Coord.), Metodología del derecho comparado. Memoria del Congreso Internacional de Culturas y Sistemas Jurídicos Comparados, Instituto de Investigaciones Jurídicas, UNAM, 2005, pp. 153-169. guiara al estudiante en la comprensión de los conceptos y principios jurídicos a través del debate nacido en las aulas. Este método activo de enseñanza se basaba en el método inductivo, donde a partir de fuentes primarias conformadas por las decisiones judiciales, el profesor debería guiar al estudiante a encontrar los principios y doctrinas derivadas de las mismas.

El método de casos de Langdell significó un gran paso de avance en el proceso de la creación docente jurídica, como ha señalado Pérez Lledó, el método de casos pone énfasis en el estudio de las fuentes primarias en lugar de manuales doctrinales, en la discusión participativa en las aulas en lugar de la pasividad y el dogmatismo de la lección magistral, en la formación metodológica y en la capacidad de argumentación jurídica en lugar de la simple memorización de información acerca de las reglas y doctrinas previamente sistematizadas ${ }^{23}$.

Sin embargo, el estudio de casos en el sistema norteamericano, se implementó a través del "libro de casos" como explica Serna de la $\mathrm{Garza}^{24}$, libros por cierto que no contenían casos sino sentencias de segunda instancia, significando ello que el estudiante o el investigador adquirían un conocimiento parcial del asunto. En la actualidad el estudio de casos según tal y como se aplica actualmente en el sistema de estudios jurídicos de los Estados Unidos ha sido sometido a muchísimas críticas dentro del ámbito de la investigación norteamericana, destacando los siguientes defectos en el sistema:

23 PÉREZ LLEDÓ, J. Antonio; "La enseñanza del derecho en Estados Unidos" Cuadernos de Filosofía, Doxa, núm. 12, 1992, p. 75.

24 SERNA DE LA GARZA, José María, "El método de casos: reflexiones sobre el cambio en la metodología de la enseñanza del derecho en México", óp. cit. pp. 154155 . 
- No deben estudiarse sentencias de última instancia sino expedientes completos en los que aparezcan los casos desde la presentación de la demanda hasta que el juicio llegue a los tribunales superiores.

- El libro de casos presenta algunos ejemplos para su discusión, pero el derecho no se contiene en unos casos únicamente ${ }^{25}$.

- Se trabaja por el profesor sobre el método analógico en la presentación de preguntas derivadas de la sentencia que se refiere el caso.

- El método de casos a través del libro de casos, se concentra en el árbol, es decir lo individual sin apreciar el bosque, considerado a éste la transdisciplinariedad ${ }^{26}$ que hemos estado defendiendo en este trabajo.

- En el método de casos es imprescindible incluir el análisis de la realidad, contrastar las conductas de las partes en cada caso concreto y cómo influyen otras circunstancias.

- El profesor Hessel E. Yntema, formuló en 1937 duras críticas a la educación jurídica estadounidense por su aislamiento cultural, limitado al método de casos y sugirió la utilización de la doctrina europea ${ }^{27}$.

25 Cfr. FRANK, Jerome, Courts on Trial, Princeton, New Jersey, 1949, pp. 225-233, citado por Zarr Melvyn en "Learning Criminal Law Through The Whole Case Method" Journal of Legal Education, vol. 34, núm. 4, 1984, p. 697.

26 Utilizamos el término de transdisciplinariedad para reafirmar la diferencia entre éste e interdisciplinariedad, en tanto, el primer término es a nuestro entender, sinónimo de materias que actúan al unísono, es decir, la sociología o psicología jurídica y el derecho, son conocimientos que están presentes en una investigación integral, sin necesidad de señalar, hasta aquí trabaja el sociólogo y entonces empieza el jurista.

27 Cfr. FIX-ZAMUDIO, Héctor; "Tendencias actuales del derecho comparado", en SERNA DE LA GARZA, José María (Coord.), Metodología del derecho comparado. Memoria del Congreso Internacional de Culturas y Sistemas Jurídicos Comparados, Instituto de Investigaciones Jurídicas, UNAM, 2005, p. 35.

\section{LA ENSEÑANZA CLÍNICA DEL DERECHO: UNA OPCIÓN LATINA ANTE EL ESTUDIO DE CASOS}

El sistema de clase activa requiere de un equipo docente de tiempo completo e interdisciplinar en las condiciones de pensamiento complejo donde estén presentes todos los representantes de las especialidades que requiera el tema.

Antes de llegar a una clase de clínica de derecho, es imprescindible en el proceso educativo abordar otras formas de enseñanzas activas, donde se haya entrenado al estudiante en las técnicas mínimas para el trabajo jurídico.

Para Jorge Witker la enseñanza clínica del derecho, no se basa en el estudio de un caso hipotético en un aula, es según este autor, un servicio profesional a alguien que lo necesita, el que presta el servicio es el estudiante bajo el control, dirección y orientación académica de los profesores ${ }^{28}$.

En coincidencia con Witker ${ }^{29}$, en una posición más objetiva, la enseñanza clínica del derecho, permite al estudiante conocer el Derecho en acción, proporcionando además una perspectiva completa y armónica del fenómeno jurídico, persiguiendo entre el objetivo más importante, integrar el estudio abstracto de la norma y la teoría a su aplicación jurídica-social real y concreta, ello en una visión de estudiante integral, permite dar paso a detectar los problemas legales de mayor trascendencia.

E1 Dr. Witker ${ }^{30}$ ha planteado en México, un diseño para implementar la enseñanza clínica, para este profesor, es factible, cuestión que comparto, incorporar al curriculum, cursos o créditos que deben cubrirse en el desarrollo

\footnotetext{
28 WITKER, Jorge, Técnicas de la enseñanza del Derecho, Op. cit., p. 145.

29 Ídem.

30 WITKER, Jorge, óp. cit., pp.146 y ss.
} 
de la carrera, constituyendo tres grupos en el desarrollo de la clínica o práctica jurídica.

I. A los alumnos de los primeros niveles, se les asignan tareas de simple recopilación de información y técnicas de estrategias con el cliente (mediación, preparación psicológica para enfrentarse a la persona que busca asesoría)

II. Para estudiantes de cursos intermedios, las tareas avanzan en complejidad y deben estar en condiciones de atender y resolver asuntos administrativos sencillos, por ejemplo ubicar un título de dominio.

III. Los estudiantes de últimos cursos, deben estar preparados para entrar en contacto directo con los órganos judiciales, entiéndase por ejemplo, contestar demandas, preparar pruebas.

Con una visión más amplia, Alicia Álvarez ${ }^{31}$, considera que la educación clínica tiene tres componentes, el primero, un bufete de abogados en el centro de estudios universitarios de derecho para que tenga la oportunidad el estudiante de practicar y aprender de esta experiencia bajo la supervisión de un docente perteneciente a la universidad; en un segundo lugar, la pasantía, permite al estudiante trabajar fuera de la universidad, en ONGs, o en oficinas de gobierno, la supervisión se realiza por un funcionario de la entidad pública o privada y un profesor. El tercer tipo de modelo es la clase de simulación, donde se presume enseñar destrezas al abogado, como por ejemplo, cómo entrevistar, asesorar.

En definitiva, y coincidiendo con Carlos Ramos González $^{32}$ el método de aprendizaje clínico

31 ALVÁREZ, Alicia, "La educación clínica. Hacia la transformación de la enseñanza del derecho", en VILLARREAL, Marta y COURTIS, Christian (Coord.), Enseñanza clínica del derecho. Una alternativa a los métodos tradicionales de formación de abogados, ITAM, México, 2007, p. 226.

32 RAMOS GONZÁLEZ, Carlos, "El método clínico: alternativa al aprendizaje por "ósmosis", en VILLA- del derecho es un proceso de integración y aprendizaje doctrinal y teórico, donde se destacan las destrezas de análisis, comunicación y persuasión.

Pero creo que es importante destacar que en el método clínico del derecho debe estar concebido a nuestro entender personal con las siguientes características:

1. La enseñanza clínica del derecho se valora como créditos dentro de la carrera de Derecho.

2. Es organizado por un grupo de profesores de tiempo completo y especialistas en ejercicio, preferiblemente, vinculados a la docencia.

3. La práctica o ejercicio de la profesión debe estar precedida de una preparación teóricapedagógica, donde se incorporan las nuevas técnicas de mediación y las características de un ejercicio en el mundo globalizado.

4. La enseñanza clínica del derecho no debe quedar limitada al ejercicio de la abogacía sino que es importante se logre y desarrolle la actividad jurídica en las distintas manifestaciones de la profesión, entiéndase, derecho empresarial, sociedad de la información, bioética y derecho, entre otros muchos reclamos socio-económicos que se le hacen al derecho hoy en día.

Pero la enseñanza clínica del derecho, necesita algo más que un diseño metodológico para incorporar a los programas de estudio de la carrera de Derecho, se necesita infraestructura a la cual se aspira en los próximos años en la carrera, sin embargo, la implementación de la enseñanza clínica del derecho, no es sólo cuestión de infraestructura, es más el trabajo conjunto de agentes políticos, económicos y gubernamentales del Estado, en el cual se

RREAL, Marta y COURTIS, Christian (Coord.), Enseñanza clínica del derecho. Una alternativa a los métodos tradicionales de formación de abogados, ITAM, México, 2007, p. 281. 
reconozca a la Universidad como formadora legítima de las fuentes de trabajo profesional, y se alimente y actualice por interés de los propios empresarios y organizaciones estatales, todo lo requerido para que el aprendizaje sea dinámico, actualizado y competitivo en el mundo globalizado donde vivimos, la Universidad es el lugar idóneo para trabajar en una investigación que facilite la propuesta de leyes por una parte y la vinculación de sus alumnos y profesores con las entidades que reflejan la realidad jurídica en el lugar donde nos encontremos, mientras no se produzca este reconocimiento, la enseñanza clínica del derecho y la investigación jurídica aplicada serán definitivamente limitadas.

\section{LA ENSEÑANZA BASADA EN COMPETENCIA: LA EXPERIENCIA EN AMÉRICA LATINA}

El modelo educativo por competencias en el área pedagógica implica un conjunto de conocimientos, habilidades y destrezas que son aplicadas al desempeño de una función profesional de forma tal que el sujeto demuestre capacidad de autodirección, responsabilidad y sepa en definitiva, resolver los problemas ${ }^{33}$. En la enseñanza universitaria se produce una tendencia que transita por otorgarle mayor protagonismo al estudiante en su proceso de formación a partir de un proceso de aprendizaje autónomo en el que se aprenda a aprender ${ }^{34}$.

Una nueva forma de aprendizaje a nivel universitario implica una dinámica concepción en los programas o currícula de las carreras, que a criterio de la autora, no deben convertirse

33 Concepto que puede inferirse en cuadro sobre competencias principales para el desempeño profesional desarrollado por CEPEDA DOVALA, Jesús Martín, en "Metodología de la enseñanza basada en competencias", Revista Iberoamericana de Educación, 34/2004, p. 4.

34 SALAS ZAPATA, Walter Alfredo; Formación por competencias en la Educación Superior. Una aproximación conceptual. Revista Iberoamericana de Educación, 2005, p. 2. en planes cerrados y sí estar inspirados en una visión constructivista ${ }^{35}$. En el área del derecho la generación de competencias para el estudiante universitario se aleja del sistema pragmático o practicista, el jurista, integral en formación, debe estar caracterizado por algo más que la oratoria o el conocimiento de los trámites procesales, debe además, estar preparado, para distinguir por ejemplo, un contrato inexistente de un contrato anulable, aún y cuando ello dependa de posiciones de política legislativa, es importante conocer también esa realidad en la transdisciplinariedad del derecho que antes señalamos.

En la Universidad Juárez Autónoma de Tabasco, en México, se trabaja este nuevo plan de determinadas competencias básicas para el jurista de hoy, destacando las siguientes:

1. Comunicación lingüística. Es obligación del jurista saber argumentar, no sólo a través del conocimiento de la lengua española sino de la especialidad que la materia requiere.

2. Conocimientos matemáticos. Estos permitirán adquirir habilidades para interpretar y expresar con claridad datos, hechos y argumentaciones, alejada de la retórica tradicional y aplicadas sí a la realidad jurídica que lo amerita.

3. Conocimiento e interacción con el mundo físico. La actividad del jurista en la actualidad ha roto el campo de lo público y lo privado, como tradicionalmente se consideraba el derecho, el ámbito social y humano permea la realidad jurídica que debe encontrar soluciones para nuevos problemas de la ciencia, salud, actividad física, consumo, y procesos tecnológicos.

4. Tratamiento de la información y competencia digital. La sociedad de la información es

35 MORA MORA, Reynaldo. Una aproximación al estado del arte de la investigación curricular. Revista de Investigación bolivariana, 2005, p. 120. 
una realidad innegable, aumenta las comunicaciones y el intercambio de información, por ello el estudiante tiene que prepararse para acceder a las fuentes informativas más confiables, aprendiendo entonces a seleccionar información.

5. Social y ciudadana. Uno de los fracasos de los métodos tradicionales de enseñanza del derecho ha sido precisamente el de distanciar el derecho de su entorno, ello ha provocado insensibilidad en el ejercicio de la profesión, e ineficacia de la norma. Con esta competencia, se trabajará para comprender la realidad social en que se vive, a través de una realidad histórica y social crítica del mundo. En esta competencia se perseguirá que los estudiantes cuenten con valores de convivencia, respetando patrones culturales básicos de cada región convivir y ejercer la ciudadanía democrática en una sociedad plural y cada vez más intercultural.

6. Aprender a aprender. Esta competencia es la que identifica y sobre la que se integran las otras competencias, donde la capacidad del pensamiento se ensancha y dinamiza. En esta competencia se distinguen las destrezas imprescindibles del egresado de derecho en la era de la globalización, donde el aislamiento intelectual ha sido superado y es preciso un trabajo creativo, ya sea que se manifieste a través de proyectos de investigación o solución de problemas, siempre considerando la sociedad de la información.

$\mathrm{Y}$ es que ciertamente, en la búsqueda de la educación por competencias ${ }^{36}$, se conjugan una serie de principios en los que destaca la conciliación del amoralismo posmoderno con la enseñanza de la convivencia, la ética, la moral, la democracia y la ciudadanía.

36 Muy interesante resulta la Conferencia dictada por VASCO U., Carlos. E, "Siete retos de la educación colombiana para el período de 2006 a 2019", Eduteka, en http://www.eduteka.org/pdfdir/RetosEducativos. pdf, consultada el 28 de enero de 2010.

\section{EXPERIENCIA EUROPEA: EL PROCESO BOLONIA}

En Europa como en América, se ha detectado un nuevo escenario cultural caracterizado por:

Un contexto crecientemente inestable.

- Una demanda progresiva de educación superior.

- La internacionalización de la educación superior e investigación.

- La emergencia de nuevas expectativas.

- La deslocalización de la producción y la distribución de conocimiento.

- La cooperación entre las Universidades y la industria.

La realidad actual identificada en el mundo académico y cultural con estas características, ha marcado el paso de la denominada universidad clásica a una universidad emprendedora ${ }^{37}$.

El proceso de Bolonia, implica para la nueva Europa, conformada por la Unión Europea una nueva perspectiva universitaria, no es un simple cambio en la forma de computar los créditos que deban cursar los estudiantes para obtener una determinada titulación oficial, sino que ha de conducir a una renovación sustancial de la metodología docente, se pasa así del actual sistema de créditos aplicados en países como España al aprendizaje del estudiante, donde se debe otorgar mayor protagonismo y autonomía al mismo y el profesor debe enseñar a aprender ${ }^{38}$.

La Unión Europea conformada por una serie de países procedentes tanto del sistema romano francés como anglosajón, han enfrentado la realidad de, no sólo homogeneizar la enseñanza

37 LÓPEZ HERRERÍA, José Ángel, La Universidad ( $Y$ el Proceso de Bolonia: E.E.U.U.) Hergué Editora Andaluza, España, 2008, p. 53.

38 GUARDIA I OLMOS; Joan; La declaración de Bolonia, Fundación ECOEM, Sevilla, España, 2007 p. 54.

Bogotá, D.C. Colombia - Volumen XII - No. 24 - Julio - Diciembre 2009 - ISSN 0121-182X 
del derecho de forma tal que todos los ciudadanos europeos puedan ejercer en cualquier lugar de este espacio, sino además, buscar la excelencia académica; para este objetivo, se pretende que en el año 2010, la Unión Europea estará más unida por medio del proceso de Bolonia, programa que pretende en el logro del espacio europeo de educación superior. La Declaración de Bolonia (1999) sentenció: "En la actualidad, la Europa del conocimiento está ampliamente reconocida como un factor irremplazable para el crecimiento social y humano y es un componente indispensable para consolidar y enriquecer a la ciudadanía europea, con capacidad para dar a sus ciudadanos las competencias necesarias para afrontar los retos del nuevo milenio, junto con una conciencia de valores compartidos y de pertenencia a un espacio social y cultural común".

La citada declaración dio paso a la Estrategia de Lisboa, que fue acordada por los miembros del Consejo Europeo en la ciudad de Lisboa en marzo del año 2000 y en la que se reconoce: "para convertirse en la economía del conocimiento más competitiva y dinámica del mundo, con capacidad para desarrollar un crecimiento sostenible, con más y mejores empleos y una mayor cohesión social". Proceso que, tal como se señala en la Declaración está encaminado a adoptar un sistema de titulaciones comprensible y comparable cuyo objetivo último es promocionar la obtención de empleo y la competitividad del sistema de educación superior europeo; la adopción de un sistema basado esencialmente en dos ciclos fundamentales: un primer ciclo orientado al mercado laboral con una duración mínima de tres años, y un segundo ciclo (máster) al que se accede sólo si se completa el primer ciclo. La revolución universitaria europea marcada por el proceso de Bolonia, incluye por ejemplo, que en lugar del crédito actual, que equivale a diez horas de clase tradicional, se toma además como referencia el trabajo del alumno incluyendo en sus 25-30 horas el tiempo no sólo de clase, sino también del que se dedica fuera de ella (estudio, tutorías, trabajos, seminarios, etc.) a la obtención del conocimiento exigido para cada título.

Dentro del proceso de Bolonia, cinco son las cuestiones de más novedad: el papel del profesor, del alumno, las metodologías activas de enseñanza, el desarrollo de competencias y el sistema de evaluación. El profesor se convierte entonces en un guía del proceso docente, y ello conlleva muchísimo esfuerzo porque cambia el rol del profesor al producirse una fusión entre el proceso de enseñanza y el proceso de aprendizaje.

La realidad europea en definitiva, coincide con la toma de consciencia de todos los profesores universitarios del mundo y sus autoridades en cuanto a la necesidad de activar la enseñanza, sin embargo el camino no es tan fácil porque de la misma forma que es necesario preparar nuevos alumnos, asimismo las autoridades universitarias están en la obligación de exigir a sus profesores la adaptación a un nuevo paradigma de la enseñanza.

En el caso de España, el Proceso de Bolonia es una norma de derecho interno que ha implicado un proceso de reforma de los planes de estudio en las Universidades españolas, por ejemplo, en la Universidad Autónoma de Madrid, lo que tradicionalmente se ha enseñado en la carrera de Derecho, no se descarta, pero se potencian los seminarios y casos prácticos, se incluye además la materia Argumentación jurídica y documentación, con seis créditos, que incluye el aprendizaje sobre redacción de escritos jurídicos con una adecuada capacidad de razonamiento en lenguaje jurídico ${ }^{39}$.

39 DIEZ-HOCHLEITNER, Javier y RODRÍGUEZ DE SANTIAGO, José María; "El proceso de Bolonia y los nuevos planes de estudios de Derecho" en Revista del Colegio Notarial de Madrid, Enero-Febrero 2009/No 23, consultado en http:/www.elnotario.com. 


\section{CONCLUSIONES}

La investigación jurídica no puede quedar reducida al análisis de la dogmática jurídica de forma tal que se valore el derecho desde una perspectiva abstracta, de igual forma "la solución al derecho" no puede estar marcada por la creación o derogación de leyes, considerando sólo la concepción positivista del derecho, la normativa.

En la investigación jurídica actual, debemos reconocer el aporte de las corrientes realistas, al reconocer el derecho como un hecho social complejo que necesita estudiarse como método propio de otras disciplinas como la sociología, la antropología, la economía, la psicología, la historia y la política. La investigación jurídica debe superar la perspectiva formalista centrada también en el lenguaje propio del derecho, pero la investigación jurídica debe estar en función de la sociedad y de la perfección de la enseñanza del derecho, para ello es importante trabajar en lo métodos activos de enseñanzas, para lograr que los estudiantes aprendan de la experiencia, cuando ellos mismos toman roles de actividad profesional, guiados por sus profesores, todo ello, basado en casos reales o muy asimilados a situaciones reales, la enseñanza clínica del derecho como modalidad de las formas de aprendizaje por competencias, es un camino pedagógicamente interesante, sin embargo, hasta que los poderes del Estado, no reconozcan a la Universidad como el lugar idóneo para trabajar en una investigación que facilite la propuesta de leyes por una parte y la vinculación de sus alumnos y profesores con las entidades que reflejan la realidad jurídica en el lugar donde nos encontremos, mientras no se produzca este reconocimiento, la enseñanza clínica del derecho y la investigación jurídica aplicada serán definitivamente limitadas.

\section{BIBLIOGRAFÍA}

ADAME GODDARD, Jorge; "Método para la solución de casos jurídicos". Revista Ars
Iuris, 37/2007. Universidad Panamericana. México.

ADEODATO, Joao Mauricio, "E1 derecho como norma ética", en Rabbi-Baldi Cabanillas, Renato (Coord.), Las razones del derecho natural, Editorial Abaco de Rodolfo de Palma, 2a Edición, 2008.

ALVÁREZ Alicia, "La educación clínica. Hacia la transformación de la enseñanza del derecho", en VILLARREAL, Marta y COURTIS, Christian (Coord.), Enseñanza clínica del derecho. Una alternativa a los métodos tradicionales de formación de abogados, ITAM, México, 2007.

ÁVILA ORTIZ, Raúl, "La metodología jurídica en México: Un estado de arte", en Cienfuegos SALGADO, David Y LÓPEZ OLVERA, Miguel A. (Coord.), Estudios en homenaje a Don Jorge Fernández Ruiz. Derecho Internacional y otros temas. UNAM, México, 2005.

AZAR, Aldo M; Propuestas de metodología jurídica. Editorial Advocatus. Argentina, 2008.

BURBANO LÓPEZ, Galo; "La educación superior en la segunda mitad del Siglo XX. Los alcances del cambio en América Latina y el Caribe" Revista Iberoamericana (OEI) No 21, Universidad Siglo XXI. Septiembre-diciembre 1999, p 20. http://www.rieoei.org/rie21f.htm

CAJAS SARRIÁ, Mario Alberto, "Minimalismo judicial: ¿Cass Sustein en la Corte Constitucional?, Cuestiones Constitucionales, México, número 20, Enero-junio de 2009.

CARRIÓ, G.R; Notas sobre derecho y lenguaje, Buenos Aires, 1990.

CEPEDA DOVALA, Jesús Martín, en "Metodología de la enseñanza basa en competencias", Revista Iberoamericana de Educación, 34/2004.

COSSÍO DÍAZ, José Ramón; Derecho y análisis económico, Editorial Fondo de Cultura Económica -ITAM, México, $2^{\mathrm{a}}$ reimpresión, 2008.

COURTIS, Christian, "El juego de los juristas. Ensayo caracterización de la investigación 
dogmática", Courtis, Christian (Ed.) Observar la ley. Ensayos sobre metodología de la investigación jurídica, Ed. Trotta, 2006.

CRUZ PARCERO, Juan Antonio, El lenguaje de los derechos, Editorial Trotta, Madrid, 2007.

DIEZ-HOCHLEITNER, Javier y RODRÍGUEZ DE SANTIAGO, José María; "E1 proceso de Bolonia y los nuevos planes de estudios de Derecho" en Revista del Colegio Notarial de Madrid, Enero-Febrero 2009/No 23.consultado en http:/www.elnotario.com.

ESCOBAR MARTÍNEZ Lina Marcela; El DERECHO A LA EDUCACIÓN EN COLOMBIA 1830-1853. LA HISTORIA EN EL PRESENTE" en Revista Prolegómenos-Derecho y Valores. Volumen XII. No 23. Colombia. Enero-Junio 2009

FIX-FIERRO, Héctor; Del Gobierno de los abogados al imperio de las leyes. Estudios sociojurídicos sobre educación y profesión jurídicas en el México contemporáneo. UNAM, 2008.

FIX-ZAMUDIO, Héctor; "Tendencias actuales del derecho comparado", en Serna de la Garza, José María (Coord.), Metodología del derecho comparado. Memoria del Congreso Internacional de Culturas y Sistemas Jurídicos Comparados, Instituto de Investigaciones Jurídicas, UNAM, 2005 .

GARCÍA JARAMILLO, Leonardo; "E1 "Nuevo Derecho en Colombia" Entelequia necesaria o novedad pertinente. Revista de Derecho. Junio No 29. Universidad del Norte. Barranquilla. Colombia, 2008.

GONZÁlEZ GALVÁN, Jorge Alberto, "Enseñanza de la metodología de la investigación aplicada al derecho:¿Ciencia jurídica o ciencia ficción? Un ensayo de autocrítica". Boletín Mexicano de Derecho Comparado, Número conmemorativo, sexagésimo aniversario. México.
GUARDIA I OLMOS; Joan; La declaración de Bolonia. Fundación ECOEM, Sevilla, España, 2007.

FRANK, Jerome, Courts on Trial, Princeton, New Jersey, 1949, pp. 225-233, citado por Zarr Melvyn en "Learning Criminal Law Through The Whole Case Method" Journal of Legal Education, vol. 34, núm. 4, 1984.

LARA CHAGOYÁN, Roberto "Argumentación jurídica e investigación en derecho", en Courtis, Christian, (Ed.) Observar la ley. Ensayos sobre metodología de la investigación jurídica, Ed. Trotta, 2006.

LÓPEZ HERRERÍA, José Ángel; La Universidad (Y el Proceso de Bolonia: E.E.U.U.) Hergué Editora Andaluza, España, 2008.

MERRYMAN, John Henry, "Fines, objeto y método del derecho comparado" traducción de Fausto F. Rodríguez García, en Boletín Mexicano de Derecho Comparado, nueva serie, año IX, número 25-26, Enero-Agosto de 1976.

- "Modernización de la ciencia jurídica comparada", en Boletín Mexicano de Derecho Comparado, nueve serie, año XVI, número 46, Enero-Abril de 1983.

MORA MORA, Reynaldo. "Una aproximación al estado del arte de la investigación curricular". Revista de Investigación bolivariana. Colombia. 2005

ORTIZ DE URBINA GIMENO, Iñigo, "E1 análisis económico del derecho: ¿Método útil o ideología nefasta? en Courtis, Christian, (Ed.) Observar la ley. Ensayos sobre metodología de la investigación jurídica, Ed. Trotta, 2006.

PEÑA GONZÁLEZ, C.; "¿Qué hacen los civilistas?", en Cuadernos de Análisis Jurídico, número 28, Facultad de Derecho, Universidad Diego Portales, Santiago de Chile, 1993.

PÉREZ LLEDÓ, J. Antonio; "La enseñanza del derecho en Estados Unidos" Cuadernos de Filosofía, Doxa, núm. 12, 1992. 
POPPER, Karl, La lógica de la investigación científica. Trad. Víctor Sánchez de Zavala, $1^{\text {a }}$ Ed., 11 a reimp. Madrid, Tecnos, 1973.

RAMOS GONZÁLEZ, Carlos, "El método clínico: alternativa al aprendizaje por "ósmosis", en VILLARREAL, Marta y COURTIS, Christian (Coord.), Enseñanza clínica del derecho. Una alternativa a los métodos tradicionales de formación de abogados, ITAM, México, 2007.

REALE, Miguel, Teoría tridimensional del derecho, Madrid, Editorial Tecnos, Octubre 1967,

REARTE, Martín, "El cambio de paradigma científico y el derecho", en Revista Ciencias Sociales, Universidad de Costa Rica, 117-118, 2007.

RECANSES, Luis: "Balance de la Teoría Pura del derecho" en Boletín Mexicano de Derecho Comparado, Instituto de Investigaciones Jurídicas. UNAM. 1974.

SALAS ZAPATA, Walter Alfredo; Formación por competencias en la Educación Superior. Una aproximación conceptual. Revista Iberoamericana de Educación, Colombia, 2005.

SERNA DE LA GARZA, José María, "E1 método de casos: reflexiones sobre el cambio en la metodología de la enseñanza del derecho en México", en Serna de la Garza, José María (Coord.), Metodología del derecho comparado. Memoria del Congreso Internacional de Culturas y Sistemas Jurídicos Comparados, Instituto de Investigaciones Jurídicas, UNAM, 2005.

VASCO U., Carlos. E, "Siete retos de la educación colombiana para el período de 2006 a 2019", Eduteka, en http://www.eduteka.org/ pdfdir/RetosEducativos.pdf, consultada el 28 de enero de 2010 .

WITKER, Jorge, "Hacia una investigación jurídica integrativa", en Boletín Mexicano de Derecho Comparado, México, nueva serie, año XLI, núm. 122, mayo-agosto de 2008.

"Algunas reflexiones en torno a la reforma curricular de los estudios jurídicos en América Latina" en Estudios en homenaje a María Muñoz de Alba Medrano, 2007, Instituto de Investigaciones UNAM, México. 2007

Técnicas de la enseñanza del Derecho. Serie J. Enseñanza del Derecho y Material Didáctico, Número 7, 4a edición, 1985, Instituto de investigaciones Jurídicas, UNAM. 